\title{
Synthesis, Degree of Substitution, and Clotting Ability of Carboxyethyl Carbamoylethyl Cellulose
}

\author{
Kenji KAMIDE, Kunihiko OKaJIMA, Toshihiko MATSUI, \\ and Masanao OHNISHI* \\ Fundamental Research Laboratory for Fibers and Fiber-Forming \\ Polymers, Asahi Chemical Industry Co., Ltd., \\ 11-7 Hacchonawate, Takatsuki, Osaka 569, Japan \\ *Ohnishi Hospital, 4-7-28 Suwa, Joto-ku, Osaka 536, Japan
}

(Received June 20, 1986)

\begin{abstract}
Acid-, sodium-, and calcium-types of carboxyethyl carbamoylethyl cellulose (CECEC) sample with various degrees of substitution by carboxyethyl group $\langle F\rangle_{\text {co }}$ or carbamoyl ethyl group $\left\langle\langle\mathrm{F}\rangle_{\mathrm{NH}}\right.$, and thus with various total degrees of substitution $\langle\vec{F}\rangle_{t}\left(\langle\mathrm{~F}\rangle_{\mathrm{CO}}+\left\langle\langle\mathrm{F}\rangle_{\mathrm{NH}}\right)\right.$ were synthesized by reacting alkali cellulose with acrylonitrile as a potential clotting materials in a solid form and coagulant in its solution. Increase of $\langle\bar{F}\rangle_{\mathrm{NH}}$ for the CECEC sample by reaction with acrylamide was also attempted in aqueous alkali solution. $\langle\mathrm{F}\rangle_{\mathrm{co}},\langle\mathrm{F}\rangle_{\mathrm{NH}}$, and $\langle\mathrm{F}\rangle_{t}$ were determined by elemental analysis. Full assignment of the peaks in ${ }^{13} \mathrm{C}$ NMR spectra was given. Methods for estimating $\langle\mathrm{F}\rangle_{\mathrm{CO}},\langle\mathrm{F}\rangle_{\mathrm{NH}}$, and $\langle\mathrm{F}\rangle_{t}$ by ${ }^{1} \mathrm{H}$ and ${ }^{13} \mathrm{C} N \mathrm{NM}$ spectroscopy were proposed. From the latter, the total degrees of substitution at $C_{2}+C_{3}$ and $C_{6}$ positions, $\left\langle\mathrm{f}_{2}\right\rangle+\left\langle\left\langle\mathrm{f}_{3}\right\rangle\right.$ and $\left\langle\mathrm{f}_{6}\right\rangle$ were determined. CECEC was discovered to have excellent topical clotting ability towards human blood and coagulating ability towards human blood plasma, as compared with carboxymethyl cellulose and gelatine. The mechainsm of the clotting was discussed in connection with $\langle\mathrm{F}\rangle_{\mathrm{co}}$ and $\langle\mathrm{F}\rangle_{\mathrm{NH}}$.

KEY WORDS Clotting Ability / Blood Plasma Coagulating Ability / Carboxyethyl Carbamoylethyl Cellulose / NMR Analysis / Degree of Substitution / Carboxymethyl Cellulose / Gelatine /
\end{abstract}

Cellulosic acids, such as 6-carboxyl cellulose (oxycellulose), and arginic acid have been widely known to accelerate the topical blood clotting. ${ }^{1,2}$ The carboxyl group constituting the above molecules promotes the absorption of serum proteins from human blood and might react directly with amino acid residues of the proteins, finally leading to topical blood clotting. ${ }^{1}$ Oxycellulose is said to absorb hemoglobin. But, the general coagulation mechanism of the blood fibrin so far established is not affected by addition of oxycellulose to the blood plasma., ${ }^{1,2}$ On the other hand, there are known some blood coagulants which actually influence the coagulation mechanism. Typical coagulants are, for exam- ple, carbazochrom salicylate, tranexamic acid and $\varepsilon$-aminocaproic acid, which have amide groups. ${ }^{2}$ Therefore, it is interesting to clarify whether the cellulose derivative having both carboxyl and amide groups in its pyranose ring shows the topical clotting and the fibrin coagulation effects or not. A derivative having both carboxyl and amide groups can be prepared by the reaction of alkalicellulose with acrylonitrile if the reaction conditions are properly chosen.

We have already studied the role of molecular characteristics of sodium cellulose sulfate on its anticoagulant activity and acute toxicity. ${ }^{3,4}$ In this article, as an extension of previous works, we report the topical blood 
clotting and blood fibrin coagulation effects of carboxyethyl carbamoylethyl cellulose (hereafter denoted as CECEC).

\section{EXPERIMENTAL}

\section{Synthesis of Carboxyethyl Carbamoylethyl Cellulose (CECEC)}

(1) NaCECEC. Four sodium salts of CECEC samples (NaCECEC) with total degree of substitution $\langle\mathrm{F}\rangle_{t}=1.18-0.28$, determined by chemical analysis, were prepared as follows: Seventy five parts of wood pulp (the viscosity-average molecular weight $\bar{M}_{v}=11.3 \times 10^{4}$ ) were dipped into 400 parts of $30 \mathrm{wt} \%$ aqueous sodium hydroxide (aq $\mathrm{NaOH})$ at $30^{\circ} \mathrm{C}$ for $20 \mathrm{~min}$ and the excess alkali was squeezed out by pressing. The resultant 200 parts of alkali cellulose (cellulose$30 \mathrm{st} \%$ aq $\mathrm{NaOH}=75: 125, \mathrm{w} / \mathrm{w})$ were mixed with 75 parts of acrylonitrile and the mixture was stirred in a kneeder at $40^{\circ} \mathrm{C}$ for $40 \mathrm{~min}$. Into the reaction mixture, 300 parts of water were added to make a solution, which was neutralized with $10 \mathrm{wt} \%$ aq acetic acid, followed by precipitation of NaCECEC with methanol. The precipitates were separated by filtration using filter paper (Toyo filter paper No. 5B), washed by methanol and dried in air. The product having $\langle\mathrm{F}\rangle_{t}=0.52$, determined by chemical analysis, was coded as NaCECEC-2. A NaCECEC having predominantly carboxylethyl substitutents $\left(\langle\mathrm{F}\rangle_{t}\right.$ $=0.28$, coded as NaCECEC-1) was obtained by hydrolyzing NaCECEC-2 homogeńeously in $10 \mathrm{wt} \%$ aq $\mathrm{NaOH}$ at $50^{\circ} \mathrm{C}$ for $4 \mathrm{~h}$. Samples coded as NaCECEC-3 and -4 were prepared by reacting 1 part of NaCECEC- 2 with 1 and 3 parts of acrylamide in 3 parts $10 \mathrm{wt} \%$ aq $\mathrm{NaOH}$ at $50^{\circ} \mathrm{C}$ for $4 \mathrm{~h}$, respectively. For NaCECEC-1, -3, and -4, the neutralization and purification processes were the same as used for NaCECEC-2. These four NaCECEC samples were confirmed by IR to be the coethers of cellulose having carboxyethyl and carbamoylethyl substituents and these sam- ples did not contain any cyanoethyl group. NaCECEC-1 was alkali soluble and remaining others were water soluble.

(2) CaCECEC and HCECEC. NaCECEC samples were converted into free acid type (HCECEC) and calcium salt type (CaCECEC) by treating with methanol containing 10 $\mathrm{wt} \%$ aq acetic acid or $30 \mathrm{wt} \%$ aq calcium chloride (methanol-aq soln (acetic acid or calcium chloride) $=70: 30, \mathrm{v} / \mathrm{v}$, at $25^{\circ} \mathrm{C}$ ), followed by washing with methanol-deionized water $\left(70: 30, \mathrm{v} / \mathrm{v}\right.$, at $\left.25^{\circ} \mathrm{C}\right)$.

\section{Chemical Analysis}

Carboxyethyl content $A$ (wt \%) was determined by back-titration of NaCECEC suspended in a given strength of aq hydrochloric acid with aq $\mathrm{NaOH}$ and carbamoylethyl content $B\left(\mathrm{wt}^{\mathrm{o}} \%\right)$ was evaluated from nitrogen content determined by elementary analysis ( $\mathrm{CHN}$ analyzer model $\mathrm{CHN} 1-\mathrm{A}$, Shimadzu Ltd., Japan). From $A$ and $B$, the total degrees of substitution by carboxyethyl group $\left(\langle F\rangle_{\text {co }}\right)$ and that of carbamoylethyl group $\left(\langle\mathrm{F}\rangle_{\mathrm{NH}}\right)$ were calculated using the following relations,

$$
\langle\mathrm{F}\rangle_{\mathrm{CO}}=\frac{44 A}{45 B}\left(\frac{162}{4400-71 B-\left(3168 A^{2} / 45\right)}\right)
$$

and

$$
\begin{gathered}
\left\langle\langle\mathrm{F}\rangle_{\mathrm{NH}}=\frac{162}{4400-71 A B-\left(3168 A^{2} / 45\right)}\right. \\
\left\langle\langle \mathrm { F } \rangle _ { t } \text { is given as } \left\langle\langle\mathrm{F}\rangle_{\mathrm{CO}}+\left\langle\langle\mathrm{F}\rangle_{\mathrm{NH}}\right.\right.\right.
\end{gathered}
$$

\section{NMR Spectroscopy}

For the solutions of NaCECEC-2, -3, and -4 in deuterium oxide $\left(\mathrm{D}_{2} \mathrm{O}\right)$, pulse Fourier transform ${ }^{1} \mathrm{H}$ and ${ }^{13} \mathrm{C}$ NMR spectra were recorded on a $400 \mathrm{MHz}$ FT-NMR spectrometer (FT-400, JEOL, Japan) under the following operating conditions:

${ }^{1} \mathrm{H}$ NMR: Homogate decoupling mode, pulse width, $12 \mu \mathrm{s} ; 45^{\circ}$ pulse, repetition, $10 \mathrm{~s}$; number of pulses, 64; reference, 3- 
(trimethylsilyl)-propansulfonic acid sodium salt (TSP) (as 0 ppm)

${ }^{13} \mathrm{C}$ NMR: ${ }^{1} \mathrm{H}$-decouple and NNE mode, pulse width, $12 \mu \mathrm{s} ; 45^{\circ}$ pulse, repetition, $2 \mathrm{~s}$; number of pulses, 20,000; reference, dioxane (as $67.4 \mathrm{ppm}$ )

In order to confirm the methylene carbon peaks, the INEPT ${ }^{5}$ mode of ${ }^{13} \mathrm{C}$ NMR was applied for NaCECEC-4, using the carbon peak at $71.4 \mathrm{ppm}$ as the inner standard peak. ${ }^{1} \mathrm{H}$ NMR spectra were also employed for determining $\langle\mid F\rangle_{\mathrm{CO}}$ and $\langle\mathrm{F}\rangle_{\mathrm{NH}}$ and the values estimated by ${ }^{1} \mathrm{H}$ NMR method were designated as $\left\langle{ }^{*} \mathrm{~F}\right\rangle_{\mathrm{CO}}$ and $\langle\overrightarrow{\mathrm{F}}\rangle_{\mathrm{NH}}$. Based on the peak assignments carried out in this study, the distribution of substituents at $\mathrm{C}_{2}, \mathrm{C}_{3}$, and $\mathrm{C}_{6}$ positions $\left(\left\langle\mathrm{f}_{k}\right\rangle(k=2,3 \text {, and } 6)^{6}\right)$ as well as $\langle\bar{F}\rangle_{\text {CO }}$ and $\langle\bar{F}\rangle_{\mathrm{NH}}$ (designated as $\left\langle\left\langle{ }^{\circ}\right\rangle_{\text {CO }}\right.$ and $\left\langle\left\langle{ }^{\circ}\right\rangle_{N H}\right)$ was also estimated by the ${ }^{13} \mathrm{C}$ NMR method.

\section{Topical Blood Clotting Test}

The regenerated cellulose films coated with the clotting agents (CECEC, gelatin, oxycellulose and so on) were used for this purpose. The coated films were prepared as follows: A cellulose film $\left(\bar{M}_{v}=9.1 \times 10^{4}\right.$; thickness, about $40 \mu \mathrm{m}$ ), regenerated from the cuprammonium cellulose solution, was dipped into deionized water at $25^{\circ} \mathrm{C}$ for $30 \mathrm{~min}$ and the wet gel film was set on the holder so that the film was tensioned uniformly. The aqueous solutions of NaCECEC-2, -3, and -4 (polymer concentration; $5 \mathrm{wt} \%$ ) were coated on the wet cellulose film and the NaCECECcoated films were dried in air. In order to make clear the influence of the cationic species of CECEC on the topical blood clotting effect, the NaCECEC-coated films were treated with methanol containing $10 \mathrm{wt} \%$ aq acetic acid (methanol-aq acetic acid $=70: 30$, $\mathrm{v} / \mathrm{v}$ ) or methanol containing $30 \mathrm{wt} \%$ aq $\mathrm{CaCl}_{2}$ $(=70: 30, \mathrm{v} / \mathrm{v})$ at room temperature for $8 \mathrm{~h}$, followed by washing with methanol, and the HCECEC-coated films and CaCECEC-coated

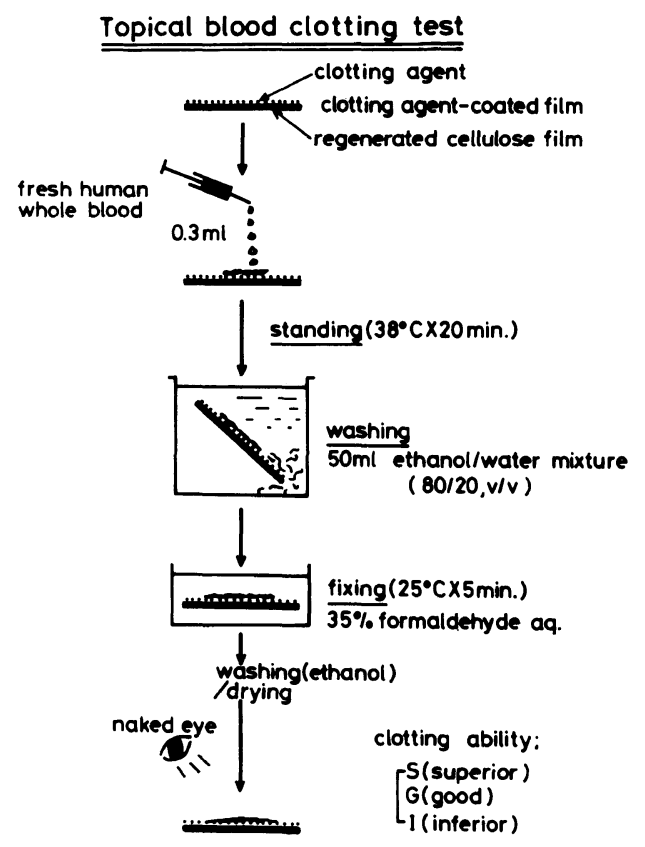

Figure 1. Schematic representation of topical blood clotting test.

films were obtained respectively. Alkali soluble NaCECEC-1 was coated on the wet cellulose film and the film was treated with methanol containing $20 \mathrm{wt} \%$ aq acetic acid (methanol-aq acetic acid $=70: 30, \mathrm{v} / \mathrm{v}$ ) at room temperature for $4 \mathrm{~h}$, washed with methanol and thus obtained HCECEC-1coated film was converted to CaCECEC1- and NaCECEC-1-coated films by treating with a mixture of methanol and $30 \mathrm{wt} \%$ aq $\mathrm{CaCl}_{2}$ or $10 \mathrm{wt} \%$ aq sodium chloride (methanol-aq solution $=70: 30, \mathrm{v} / \mathrm{v}$ ) at room temperature for $4 \mathrm{~h}$, followed by washing with methanol-water mixture $(80: 20, \mathrm{v} / \mathrm{v})$ at room temperature. As reference topical clotting agents, gelatin (Lily Inc., U.S.A.) and oxycellulose (Park-Davis Inc., U.S.A.) were also coated on the cellulose film. The gelatincoated film was obtained by only applying aq solution of gelatin (polymer concentration; $5 \mathrm{wt} \%$ ) onto cellulose film and drying in air. For the preparation of the oxycellulose-coated film, a solution of oxycellulose in $5 \mathrm{wt} \%$ aq 
$\mathrm{NaOH}$ (polymer concentration; $5 \mathrm{wt} \%$ ) was coated on the wet cellulose film and quickly treated with methanol containing $10 \mathrm{wt} \%$ aq acetic acid. A topical clotting test, as illustrated in Figure 1, was carried out as follows:

$0.3 \mathrm{ml}$ of human whole blood, freshly taken, was dropped onto the clotting agentcoated films, stood for $20 \mathrm{~min}$ in air controlled to $37^{\circ} \mathrm{C}$ and the blood not adhering to the coated films was washed out with $50 \mathrm{ml}$ of ethanol-water $(80: 20, \mathrm{v} / \mathrm{v})$ mixture at room temperature, and the blood adhering to the coated film was fixed by treating with $35 \%$ aq formaldehyde at $25^{\circ} \mathrm{C}$ for $5 \mathrm{~min}$, followed by washing with ethanol and dried in air. The degree of clotting was judged by the amount of clots formed on the coated film with the naked eye and the results were assorted into following three categories and compared with those for the gelatin-coated film:

S(superior) : A predominant part of blood added is clotted on the film surface

E(equivalent): Almost half of the blood added is clotted on the film surface

I(inferior) : Only a trace of the blood or no blood remains on the film surface

Typical films obtained were spattered by gold( $\mathrm{Au})$ under the those operating conditions: $10^{-2} \mathrm{mmHg}, 6 \mathrm{kV}, 1.2 \mathrm{~mA}$ and subjected to the observation by the scanning electron microscopy (SEM) (JSM-35CF, JEOL, Japan).

\section{Blood Plasma Coagulation Test}

$0.01 \mathrm{ml}$ of $0.2 \mathrm{wt}^{\circ} \%$ aq solution of CECEC samples was put into the test tube $(10 \mathrm{ml}$, inner diameter; $1.0 \mathrm{~cm}$ ) prewarmed at $37^{\circ} \mathrm{C}$, and $0.1 \mathrm{ml}$ of cephaloplastin (actin) (Diagnostic Inc., U.S.A., origin; dehydrated rabbit brain) and $0.1 \mathrm{ml}$ of the diluted plasma were put into the tube. The mixture was incubated at $37^{\circ} \mathrm{C}$ for $2 \mathrm{~min}$ and then, into the tube $0.1 \mathrm{ml}$ of

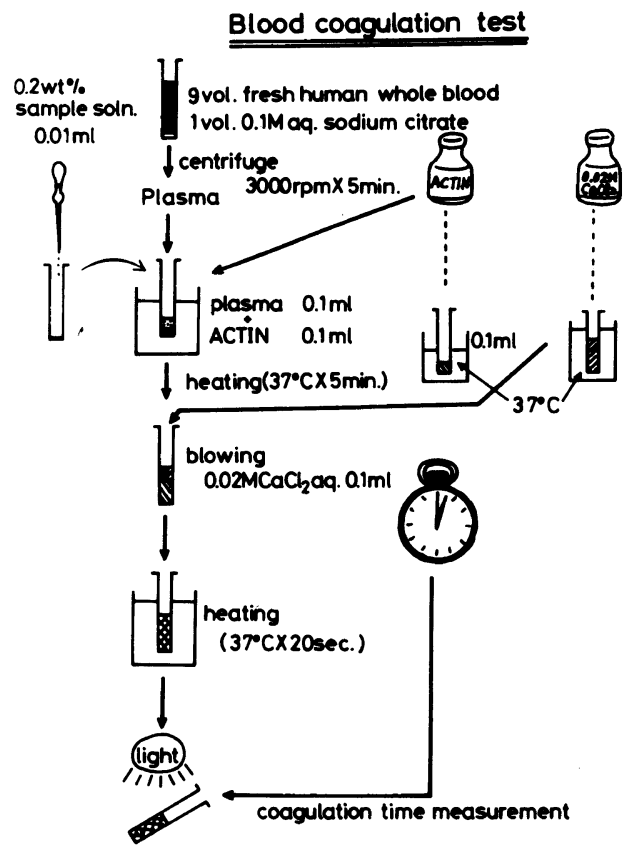

Figure 2. Schematic representation of blood plasma coagulation test.

$0.02 \mathrm{M} \mathrm{aq} \mathrm{CaCl}_{2}$ was blown. After the blowing of aq $\mathrm{CaCl}_{2}$, the time (in s) until fibrin started to grow $t_{\mathrm{f}}$ was measured. Actin was used to detect the existence of possible interaction of factor VIII, IX, XI, XII in the plasma with sample. In this procedure, the plasma was prepared by centrifuging the mixture of fresh human blood $-0.1 \mathrm{M}$ aq sodium citrate $(=9: 1, \mathrm{v} / \mathrm{v})$ at $25^{\circ} \mathrm{C}$ for $10 \mathrm{~min}$. One volume of the plasma was diluted with 5 volumes of Owrenveronal buffer (Diagnostic Inc., U.S.A.) and the diluted plasma was used for the above test. The test was carried out only for the water soluble samples. The whole procedures is illustrated in Figure $2 .^{7}$

\section{RESULTS AND DISCUSSION}

Table I shows the $\langle\bar{F}\rangle_{t},\langle\bar{F}\rangle_{\text {co }}$, and $\langle\mathrm{F}\rangle_{\mathrm{NH}}$ values of CECEC samples determined by chemical analysis. Both the $\langle\mathrm{F}\rangle_{\mathrm{CO}}$ and $\langle\mid F\rangle_{\mathrm{NH}}$ increase in the following order: CECEC- $1<$ CECEC- $<$ CECEC-3 $<$ CECEC- 
Synthesis, DS, and Clotting Ability of CECEC

Table I. Degree of substitution of CECEC by various methods

\begin{tabular}{|c|c|c|c|c|c|c|c|c|c|}
\hline \multirow{2}{*}{ Sample } & \multicolumn{3}{|c|}{ Chem. Anal. } & \multicolumn{3}{|c|}{${ }^{1} \mathrm{H}$ NMR } & \multicolumn{3}{|c|}{${ }^{13} \mathrm{C}$ NMR } \\
\hline & $\langle\mathrm{F}\rangle_{t}$ & $\langle\mathrm{~F}\rangle_{\text {CO }}$ & $\langle\mathrm{F}\rangle_{\mathrm{NH}}$ & $\langle\mathrm{F}\rangle_{t}$ & $\left\langle{ }^{*}\right\rangle_{C O}$ & $\langle\stackrel{*}{F}\rangle_{N H}$ & $\langle\stackrel{\circ}{\mathrm{F}}\rangle_{t}$ & $\langle\stackrel{\circ}{\mathrm{F}}\rangle_{\mathrm{CO}}$ & $\langle\stackrel{\circ}{\mathrm{F}}\rangle_{\mathrm{NH}}$ \\
\hline CECEC-1 & 0.28 & 0.27 & 0.01 & - & - & - & - & - & - \\
\hline CECEC-2 & 0.60 & 0.40 & 0.20 & 0.62 & 0.48 & 0.14 & 0.54 & 0.46 & 0.08 \\
\hline CECEC-3 & 0.82 & 0.43 & 0.39 & 0.85 & 0.44 & 0.41 & 0.80 & 0.58 & 0.22 \\
\hline CECEC-4 & 1.51 & 1.08 & 0.43 & 1.53 & 1.06 & 0.47 & 1.67 & 1.46 & 0.21 \\
\hline
\end{tabular}

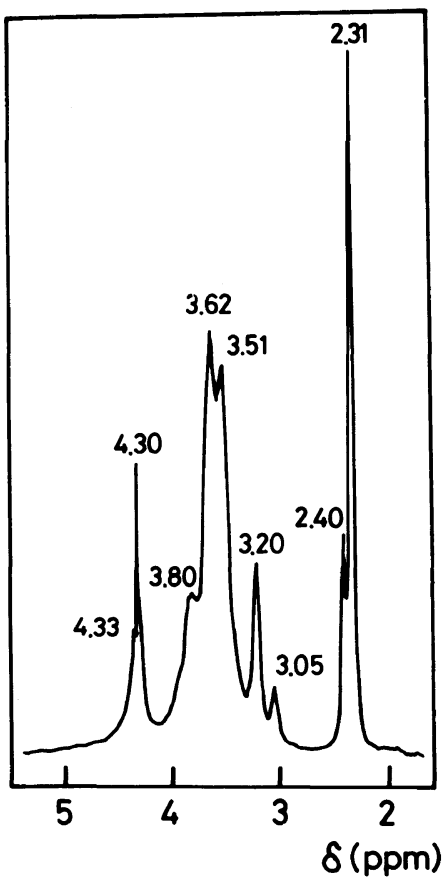

Figure 3. Typical ${ }^{1} \mathrm{H}$ NMR spectrum of NaCECEC (NaCECEC-4). Values on peaks denote chemical shifts.

4. For all the samples $\langle\bar{F}\rangle_{\mathrm{CO}}$ is larger than $\langle\mathrm{F}\rangle_{\mathrm{NH}}$. CECEC-1 has practically no carbamoylethyl group and can be regarded as carboxyethyl cellulose (CEC).

Figure 3 shows a typical ${ }^{1} \mathrm{H}-\mathrm{NMR}$ spectrum of NaCECEC-4. $\alpha$-Methylene protons for carboxyethyl $\left(-\mathrm{O}-\mathrm{CH}_{2}-\mathrm{CH}_{2}^{*} \mathrm{COONa}\right)$ and carbamoylethyl $\left(-\mathrm{O}-\mathrm{CH}_{2}-\mathrm{CH}_{2} \mathrm{CONH}_{2}\right)$ groups are expected to resonate at around 2.25$2.71 \mathrm{ppm}$, the latter being located slightly at a lower magnetic field than the former.
The above anticipation was attained by considering the shielding effects on $\mathrm{CH}_{4}(0.23$ ppm) due to $-\mathrm{COONa}(1.55 \mathrm{ppm}),-\mathrm{CONH}_{2}$ (1.59 ppm), and $-\mathrm{CH}_{2} \mathrm{OR}$ (2.93 ppm) or $-\mathrm{CH}_{3}$ (0.47 ppm) substituents. ${ }^{8}$ For CECEC, two peaks at 2.31 and $2.40 \mathrm{ppm}$ can be assigned for $\alpha$-methylene protons of carboxyethyl and carbamoylethyl substituents, respectively. The assignment seems reasonable because the peak at $2.31 \mathrm{ppm}$ is much more intense than the

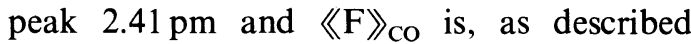
above, always larger than $\langle\bar{F}\rangle_{\mathrm{NH}}$. $\beta$-Methylene protons for carboxyethyl $\left(-\mathrm{O}-\mathrm{CH}_{2} \mathrm{CH}_{2} \mathrm{COO}-\right.$ $\mathrm{Na})$ and carbamoylethyl $\left(-\mathrm{O}-\mathrm{CH}_{2}-\mathrm{CH}_{2} \mathrm{CO}-\right.$ $\mathrm{NH}_{2}$ ) are expected to appear in the region $3.46-3.86$ and $3.52-4.06 \mathrm{ppm}$, respectively, both overlapping the peaks from glucose ring protons The ratio of peak intensity at 2.31 to that at $2.40 \mathrm{ppm}$ is a direct measure of the composition for both substituents. The peak appeared at $4.33 \mathrm{ppm}$ is due to HOD used as solvent. The total degree of substitution $\left\langle{ }^{*}\right\rangle_{t}$ by ${ }^{1} \mathrm{H}$ NMR method, can be estimated using the following equation:

$$
\langle\mathrm{F}\rangle_{t}=7 I_{2.31-2.40} / 2\left(I_{2.80-4.35}-I_{2.31-2.40}\right)
$$

where $I_{2.31-2.40}$ means the peak intensity in the range $2.31-2.40 \mathrm{ppm}, I_{2.80-4.35}$, the peak intensity in the range $2.80-4.35 \mathrm{ppm}$. $\left\langle{ }^{*} \mathrm{~F}\right\rangle_{\mathrm{CO}}$ and $\left\langle{ }^{*} \mathrm{~F}\right\rangle_{\mathrm{NH}}$ can be easily estimated from the $\langle\vec{F}\rangle_{t}$ data and the ratio of the peak intensity at $2.31 \mathrm{ppm}$ to that at $2.40 \mathrm{ppm}$. The 


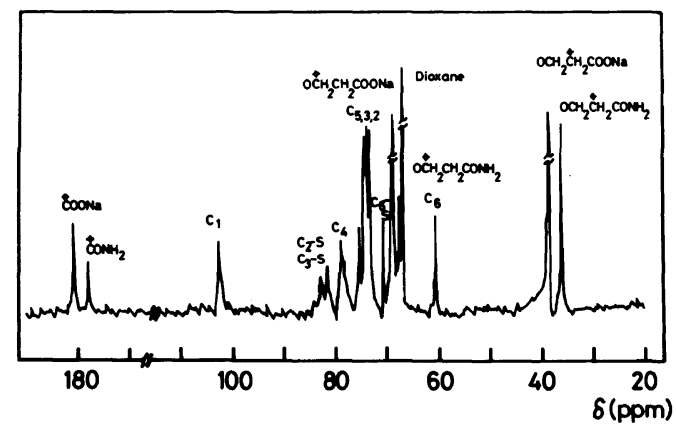

Figure 4. Typical ${ }^{13} \mathrm{C}$ NMR spectrum of NaCECEC (NaCECEC-4). Peak assignment is given in the spectrum suffix $\mathrm{S}$ means substituted ring carbon of glucopyranose unit.

results on $\left\langle{ }^{*}\right\rangle_{t},\left\langle{ }^{*}\right\rangle_{\mathrm{CO}}$, and $\left\langle{ }^{*} \mathrm{~F}\right\rangle_{\mathrm{NH}}$, determined by ${ }^{1} \mathrm{H}$ NMR are listed in the fifth-seventh columns of Table I. $\left\langle{ }^{*}\right\rangle_{c o}$ and $\left\langle{ }^{*}\right\rangle_{N H}$ are in fairly good agreements with those determined by chemical analysis.

Figure 4 shows a typical ${ }^{13} \mathrm{C}$ NMR spectrum of NaCECEC-4. The peaks at 70.9, $69.2,68.3,67.8,38.3$ and $37.4 \mathrm{ppm}$ were confirmed to be attributed to methylene carbons by INEPT mode measurement. The peaks at 38.3 and $37.4 \mathrm{ppm}$ are attributable either to $\alpha$-methylene carbon of carboxyethyl or that of carbamoylethyl substituents. Since the former peak is by far more intense than that of the latter, the former peak should be assigned to the $\alpha$-methylene carbon of the carboxyethyl substituent. The corresponding $\beta$-methylene carbon peak was observed at $69.2 \mathrm{ppm}$, of which the peak intensity was almost the same as that of the peak at 38.3 ppm. $\beta$-Methylene carbon peak responsible for carbamoylethyl substituent might be included in the peak at $67.4 \mathrm{ppm}$, overlapping the peak for dioxane used as reference (67.4 ppm). The peaks at 70.9 and $60.8 \mathrm{ppm}$ can be assigned to the substituted and unsubstituted $\mathrm{C}_{6}$ carbons in glucopyranose ring, respectively.

Since the shielding effects of carboxyethyl and carbamoylethyl substituents on $\mathrm{C}_{6}$ car- bon were anticipated not to be much different from each other, the substituted $\mathrm{C}_{6}$ carbon peak might not separate by the difference in the substituent group. In this connection, it should be noted that by a close inspection of the peaks at 38.3 and $37.4 \mathrm{ppm}$, they were found to have a shoulder peak at a higher magnetic field side of each peak, probably reflecting the difference in the position substituted with these substituents. However, at this moment, it is difficult to assign the peaks by the idea described above. Carbonyl and amide carbon peaks are seen at 180.4 and $177.7 \mathrm{ppm}$, respectively. The former peak is larger than the latter in its intensity. Other peaks were found to be derived from ring carbons constituting the glucopyranose unit by considering the literature data on cellulose and cellulose ethers. ${ }^{9-12}$ Thus, $C_{1}$ and $C_{4}$ carbon peaks appeared at 103.1 and 79.3 ppm, respectively. In the $C_{2}, C_{3}$, and $C_{5}$ carbon peak region, 4 peaks at $75.6,75.0$, 74.3 , and $78.3 \mathrm{ppm}$ were observed. The last peak is probably attributable to unsubstituted $\mathrm{C}_{2}$ carbon. The peaks at 84.3 and $82.3 \mathrm{ppm}$ are assignable to substituted $\mathrm{C}_{3}$ and $\mathrm{C}_{2}$ carbons, respectively, as observed in the most cellulose ethers. ${ }^{11,12}$ Peak separation of these two peaks for NaCECEC with lower $\langle\mathrm{F}\rangle_{t}$ was found to be inadequate for calculation of peak intensity. Peak assignments and peak intensities of ${ }^{13} \mathrm{C}$ NMR spectra of NaCECEC samples are listed in Table II. Here, the intensity of $C_{1}$ carbon peak was taken as unity. If the Overhauser effects on $C_{1}$ carbon and $\alpha$-methylene carbons of carboxyethyl and carbamoylethyl substituents can be assumed to be the same, the relative intensities for the $\alpha$-methylene carbon peaks should be a direct measure of $\langle\mathrm{F}\rangle_{\mathrm{CO}}$ and $\langle\mathrm{F}\rangle_{\mathrm{NH}}$ (hereafter referred to as $\langle\overrightarrow{\mathrm{F}}\rangle_{\mathrm{CO}}$ and $\langle\overrightarrow{\mathrm{F}}\rangle_{\mathrm{NH}}$, respectively), whose values are included in Table I. The total degree of substitution $\langle\mathrm{F}\rangle_{t}$, determined by ${ }^{13} \mathrm{C}$ NMR is in fairly good agreement with those determined by ${ }^{1} \mathrm{H}$ NMR and chemical analysis, but the 
Table II. Peak assignment and peak intensity of ${ }^{13} \mathrm{C}$ NMR spectra

\begin{tabular}{|c|c|c|c|c|}
\hline \multirow{2}{*}{ Peak in ppm } & \multirow{2}{*}{ Assignment } & \multicolumn{3}{|c|}{ Peak intensity } \\
\hline & & CEC-2 & CEC-3 & CEC-4 \\
\hline 180.4 & $-\stackrel{*}{\mathrm{COOONa}}$ & 0.20 & 0.32 & 0.76 \\
\hline 177.7 & $-\stackrel{*}{\mathrm{CONH}}{ }_{2}$ & 0.08 & 0.22 & 0.19 \\
\hline 103.1 & $\mathrm{C}_{1}$ & 1.00 & 1.00 & 1.00 \\
\hline 84.3 & $\mathrm{C}_{3}$ (substituted) & 0.07 & 0.10 & 0.42 \\
\hline 82.3 & $\mathrm{C}_{2}$ (substituted) & 0.28 & 0.37 & 0.72 \\
\hline 79.3 & $\mathrm{C}_{4}$ & 0.65 & 0.63 & 0.57 \\
\hline \multicolumn{5}{|l|}{75.7} \\
\hline 75.0 & $\mathrm{C}_{2}, \mathrm{C}_{3}, \mathrm{C}_{5}$ (unsubstituted) & 3.21 & 3.04 & 3.10 \\
\hline 74.3 & $C_{2}, C_{3}, c_{5}($ ansudosituter) & 3.21 & 5.04 & 5.10 \\
\hline \multicolumn{5}{|l|}{73.8} \\
\hline 70.9 & $\mathrm{C}_{6}$ (substituted) & 0.13 & 0.22 & 0.47 \\
\hline 69.2 & $-\mathrm{OC}^{*} \mathrm{H}_{2} \mathrm{CH}_{2} \mathrm{COONa}$ & 0.44 & 0.43 & 1.46 \\
\hline 67.8 & $-\mathrm{OC}^{*} \mathrm{H}_{2} \mathrm{CH}_{2} \mathrm{CONH}_{2}$ (overlapped with dioxane) & - & - & - \\
\hline 60.9 & $\mathrm{C}_{6}$ (unsubstituted) & 0.87 & 0.59 & 0.50 \\
\hline 38.3 & $-\mathrm{OCH}_{2} \stackrel{*}{\mathrm{C}} \mathrm{H}_{2} \mathrm{COONa}$ & 0.46 & 0.43 & 1.46 \\
\hline 36.4 & $-\mathrm{OCH}_{2} \stackrel{*}{\mathrm{C}} \mathrm{H}_{2} \mathrm{CONH}_{2}$ & 0.08 & 0.30 & 0.21 \\
\hline
\end{tabular}

$\langle\mathrm{F}\rangle_{\mathrm{NH}}$ is always smaller than those by ${ }^{1} \mathrm{H}$ NMR. This strongly suggests that during the long measuring time for ${ }^{13} \mathrm{C}$ NMR spectrum, the carbamoylethyl group was converted into carboxyethyl group by trace alkali probably existing in the solution. From Table II, it is seen that the Overhauser effects on $\alpha$-methylene carbon and amide carbonyl carbon of carbamoylethyl substituent are almost the same, but the effect on carbonyl carbon in carboxyethyl substituent is roughly half that for $\alpha$-methylene carbon of the substituent. Since the Overhauser effect seems to be different depending on the carbon species, it is difficult to determine the average probability of each substituent occupying the $\mathrm{C}_{2}$, $\mathrm{C}_{3}$, and $\mathrm{C}_{6}$ positions $\left(\left\langle\mathrm{f}_{k}\right\rangle_{\mathrm{CO}}\right.$ and $\left\langle\mathrm{f}_{k}\right\rangle_{\mathrm{NH}}$ $(k=2,3$, or 6$))$. Nevertheless, total $\left\langle\mathrm{f}_{k}\right\rangle$ $\left(\left\langle\mathrm{f}_{k}\right\rangle_{t}=\left\langle\left\langle\mathrm{f}_{k}\right\rangle_{\mathrm{CO}}+\left\langle\mathrm{f}_{k}\right\rangle_{\mathrm{NH}}(k=2,3\right.\right.$, or 6$\left.)\right) \mathrm{can}$ be roughly estimated by the following equations:

$$
\begin{aligned}
& \left\langle\mathrm{f}_{6}\right\rangle_{t}=\frac{I_{70.9}}{I_{60.9}+I_{70.9}} \\
& \left\langle\left\langle\mathrm{f}_{2}\right\rangle_{t}+\left\langle\left\langle\mathrm{f}_{3}\right\rangle_{t}=\left\langle\langle\mathrm{F}\rangle_{t}-\left\langle\left\langle\mathrm{f}_{6}\right\rangle_{t}\right.\right.\right.\right.
\end{aligned}
$$

where $I_{60.9}$ and $I_{70.9}$ are the peak intensities for the peaks at 60.9 and $70.9 \mathrm{ppm}$, respectively,

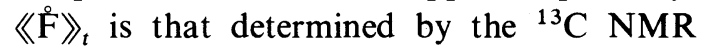
method. Here, we assume the same Overhauser effect on both substituted and unsubstituted $\mathrm{C}_{6}$ carbons. The results on $\left\langle\mathrm{f}_{6}\right\rangle_{t}$ and $\left\langle\mathrm{f}_{2}\right\rangle_{t}+\left\langle\left\langle\mathrm{f}_{3}\right\rangle_{t}\right.$ for NaCECEC samples are collected in Table III.

Figure 5 shows typical SEM photographs of the topical blood clotting formed on the sample-coated films. Untreated film, denoted as Bem (blood) in the figure, showed very slight clotting, while the HCECEC-2-coated film revealed a considerably thicker clotting than the gelatin-coated-film. Although the clotting on oxycellulose-coated film was found to be very slight with the naked eye, SEM observation showed clearly the adherence of blood serum components on the film. NaCMC-coated film proved to have a potential clotting ability. The degree of clotting for sample-coated films is also listed in Table III. The results of the blood plasma coagulation time obtained for the water soluble samples are also included in the 
Table III. Molecular characteristics, topical clotting, and blood plasma coagulation time

\begin{tabular}{|c|c|c|c|c|c|c|c|}
\hline Sample & $\langle F\rangle_{t}$ & $\langle\mathrm{~F}\rangle_{\text {co }}$ & $\langle\mathrm{F}\rangle_{\mathrm{NH}}$ & $\left\langle\mathrm{f}_{6}\right\rangle_{t}$ & $\left\langle\mathrm{f}_{2}\right\rangle_{t}+\left\langle\left\langle\mathrm{f}_{3}\right\rangle_{t}\right.$ & Clotting ability & $\begin{array}{c}\text { Coagulation time } \\
t_{\mathrm{f}} / \mathbf{s}\end{array}$ \\
\hline $\begin{array}{l}\text { HCECEC-1 } \\
\text { NaCECEC-1 } \\
\text { CaCECEC-1 }\end{array}$ & 0.28 & 0.27 & 0.01 & - & - & $\begin{array}{l}E-I \\
E-I \\
E-I\end{array}$ & $\begin{array}{l}- \\
- \\
-\end{array}$ \\
\hline $\begin{array}{l}\text { HCECEC-2 } \\
\text { NaCECEC-2 } \\
\text { CaCECEC-2 }\end{array}$ & 0.60 & 0.40 & 0.20 & 0.13 & 0.41 & $\begin{array}{l}S \\
S \\
S\end{array}$ & $\begin{array}{l}68.9 \\
76.7 \\
77.2\end{array}$ \\
\hline $\begin{array}{l}\text { HCECEC-3 } \\
\text { NaCECEC-3 } \\
\text { CaCECEC-3 }\end{array}$ & 0.82 & 0.43 & 0.28 & 0.28 & 0.54 & $\begin{array}{l}\mathrm{S} \\
\mathrm{S} \\
\mathrm{S}\end{array}$ & $\begin{array}{l}66.8 \\
65.8 \\
72.1\end{array}$ \\
\hline $\begin{array}{l}\text { HCECEC-4 } \\
\text { NaCECEC-4 } \\
\text { CaCECEC-4 }\end{array}$ & 1.51 & 1.08 & 0.43 & 0.47 & 1.20 & $\begin{array}{c}\mathrm{E}-\mathrm{I} \\
\mathrm{S} \\
\mathrm{S}\end{array}$ & $\begin{array}{l}600 \\
77.1 \\
80.1\end{array}$ \\
\hline Oxycell. & - & - & - & - & - & I & - \\
\hline Gelatin & - & - & - & - & - & $\mathrm{E}$ & 93.6 \\
\hline $\begin{array}{l}\text { HCMC } \\
\text { NaCMC } \\
\text { CaCMC } \\
\text { Blank }\end{array}$ & 0.63 & 0.63 & - & - & - & $\begin{array}{c}\text { E-I } \\
\text { E-S } \\
\text { E-I } \\
-\end{array}$ & $\begin{array}{l}90.3 \\
88.1 \\
84.2 \\
95.0\end{array}$ \\
\hline
\end{tabular}

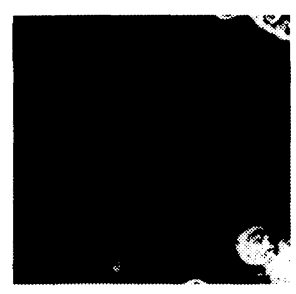

(A)

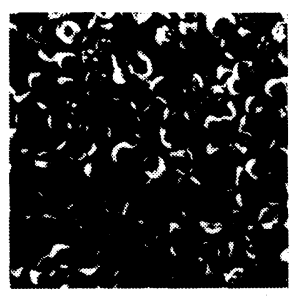

(C)

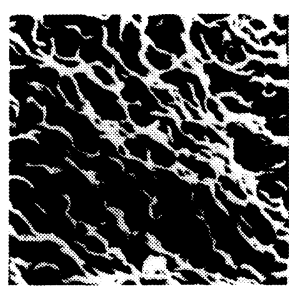

(B)

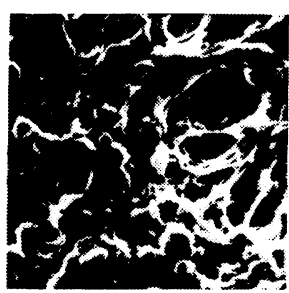

(D)
Figure 5. The typical SEM photographs of the topical clotting formed on the sample-coated films. (A), no treated original regenerated film (Bem (blood)); (B), HCECEC-2-coated film; (C), oxycellulose-coated film; (D), gelatin-coated film. table.

Table III shows that CECEC with $\langle\mathrm{F}\rangle_{t}$ more than 0.6 has an excellent clotting ability, independent of the salt type. When CECEC-2 $\left(\langle\mathrm{F}\rangle_{\mathrm{CO}}=0.4\right.$ and $\left.\langle\mathrm{F}\rangle_{t}=0.6\right)$ is compared with $\mathrm{CMC}$ having the same $\langle\mathrm{F}\rangle_{t}\left(=\langle\overline{\mathrm{F}}\rangle_{\text {co }}\right.$ $=0.63)$, CECEC -2 has higher clotting ability than CMC. This means that the carbamoylethyl group plays an important role in topical clotting ability. That is, when $\langle\mathrm{F}\rangle_{\mathrm{NH}}$ is zero the clotting ability is at most $\mathrm{E}$ or E-S unitl $\langle\mathrm{F}\rangle_{\mathrm{CO}}=0.63$, while the clotting ability is $\mathrm{S}$ when $\langle F\rangle_{N H}$ is more than 0.2 , being far smaller than'that for $\langle\mathrm{F}\rangle_{\mathrm{co}}$.

In the plasma coagulation ability test, judging from the coagulation time obtained, gelatin a typical blood clotting agent seemed to have no blood plasma coagulation ability. On the one hand, all CECEC samples except HCECEC-4 were found to promote considerably the plasma coagulation. But the procedure employed here is very liable to the experimental conditions; there is a possibility 
of the interaction of sample with actin itself, since actine is also protein. HCECEC-4 has unexpectedly high anti-coagulant activity, but the reason is not fully known at present. When compared at the same $\langle F\rangle_{t}$ level, calcium salt type of CECEC has a little lower coagulation ability than free acid and sodium salt types of CECEC, probably due to poorer solubility of CaCECEC in blood. Among the CECEC samples, CECEC with $\langle\mathrm{F}\rangle_{t}=0.82$ is the most powerful coagulation agent. All CECEC samples which were subjected to the test proved to have higher plasma coagulation ability than CMC. This also strongly suggests that the amide group in carbamoylethyl group plays a paramount role in blood plasma coagulation ability. The ability of CECEC might be related to $\langle\bar{F}\rangle_{t},\langle\bar{F}\rangle_{\mathrm{CO}},\langle\bar{F}\rangle_{\mathrm{NH}},\left\langle\left\langle\mathrm{f}_{6}\right\rangle_{t}\right.$, $\left\langle\left\langle f_{2}\right\rangle_{t}+\left\langle\left\langle f_{3}\right\rangle_{t}\right.\right.$ or the distribution of carboxyethyl or carbamoylethyl substituent at $\mathrm{C}_{6}$ or $\mathrm{C}_{2}+\mathrm{C}_{3}$ positions $\left(\left\langle\mathrm{f}_{6}\right\rangle_{\mathrm{co}},\left\langle\mathrm{f}_{6}\right\rangle_{\mathrm{NH}},\left(\left\langle\mathrm{f}_{2}\right\rangle\right.\right.$ $+\left\langle\left\langle\mathrm{f}_{3}\right\rangle\right)_{\mathrm{CO}}$, or $\left(\left\langle\mathrm{f}_{2}\right\rangle+\left\langle\left\langle\mathrm{f}_{3}\right\rangle\right)_{\mathrm{NH}}\right.$, respectively).

Figure 6 shows the plasma coagulation time as a function of these parameters. Here, the distribution of carboxyethyl and carbamoylethyl at $\mathrm{C}_{6}$ and $\mathrm{C}_{2}+\mathrm{C}_{3}$ were calculated under the assumption that $\left\langle\mathrm{f}_{6}\right\rangle_{\mathrm{CO}} /$ $\left\langle\mathrm{f}_{6}\right\rangle_{\mathrm{NH}}=\left(\left\langle\mathrm{f}_{2}\right\rangle+\left\langle\left\langle\mathrm{f}_{3}\right\rangle\right)_{\mathrm{CO}} /\left(\left\langle\mathrm{f}_{2}\right\rangle+\left\langle\mathrm{f}_{3}\right\rangle\right)_{\mathrm{NH}}\right.$

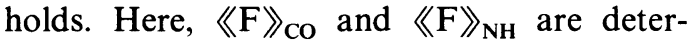
mined by chemical analysis. All curves in Figure 6 show an apparent convex having minimum, although the data points are few. It is obviously premature to decide which factor dominantly influences the plasma coagulation ability, but at the point where the coagulation time becomes apparently minimum, $\quad\langle F\rangle_{\mathrm{CO}}=\left\langle\langle F\rangle_{\mathrm{NH}}, \quad\left\langle\mathrm{f}_{6}\right\rangle_{\mathrm{CO}}=\left\langle\left\langle\mathrm{f}_{6}\right\rangle_{\mathrm{NH}}\right.\right.$, $\left(\left\langle\mathrm{f}_{2}\right\rangle+\left\langle\left\langle\mathrm{f}_{3}\right\rangle\right\rangle\right)_{\mathrm{CO}}=\left(\left\langle\mathrm{f}_{2}\right\rangle+\left\langle\left\langle\mathrm{f}_{3}\right\rangle\right)_{\mathrm{NH}}\right.$ seems to hold roughly. Anyway, it can be said there might be a proper combination of carbamoylethyl and carboxyethyl groups in order to impair the excellent blood plasma coagulation ability of CECEC.

Summarizing, a cellulose derivative having both carboxyl and amide groups expectedly shows both the topical clotting and the blood
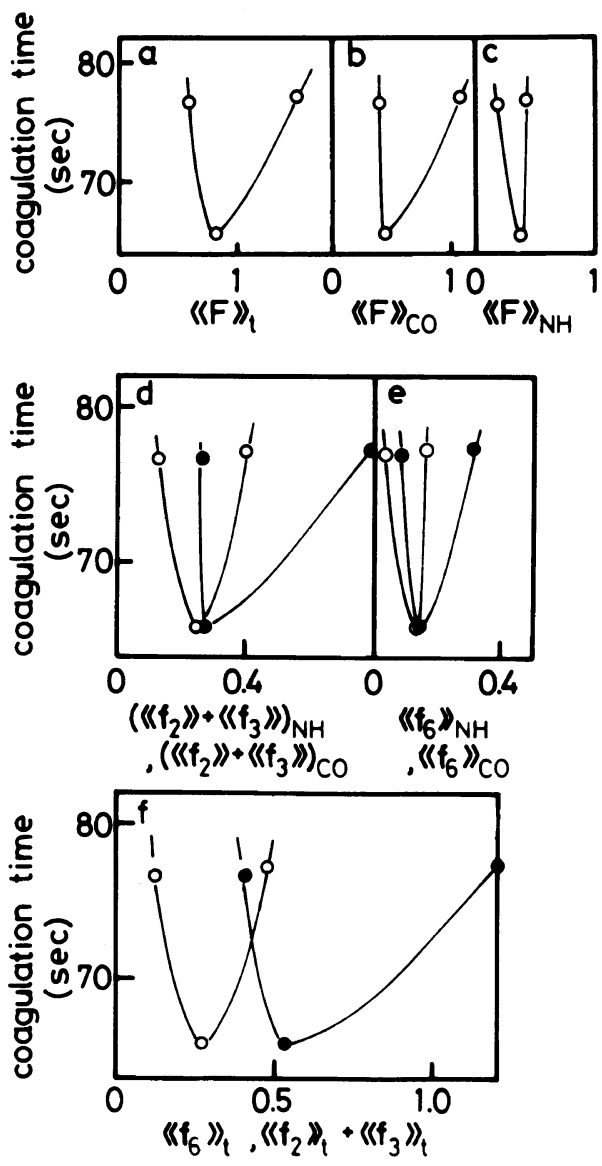

Figure 6. Plot of coagulation time as a function of parameters representing several degree of substitutions. $\mathrm{a},\left\langle\langle\mathrm{F}\rangle_{t} ; \mathrm{b},\left\langle\langle\mathrm{F}\rangle_{\mathrm{co}} ; \mathrm{c},\langle\mathrm{F}\rangle_{\mathrm{NH}} ; \mathrm{d}, \mathrm{O},\left(\left\langle\mathrm{f}_{2}\right\rangle+\left\langle\left\langle\mathrm{f}_{3}\right\rangle_{\mathrm{NH}} ; \mathbf{O}\right.\right.\right.\right.$, $\left(\left\langle\mathrm{f}_{2}\right\rangle+\left\langle\left\langle\mathrm{f}_{3}\right\rangle\right)_{\mathrm{co}} ; \mathrm{e}, \mathrm{O},\left\langle\mathrm{f}_{6}\right\rangle_{\mathrm{NH}} ; \mathrm{O},\left\langle\mathrm{f}_{6}\right\rangle_{\mathrm{co}}\right.$, and $\mathrm{f}, \mathrm{O}$, $\left\langle\mathrm{f}_{6}\right\rangle_{t} ; \bigcirc,\left\langle\mathrm{f}_{2}\right\rangle_{t}+\left\langle\left\langle\mathrm{f}_{3}\right\rangle_{t}\right.$.

plasma coagulation abilities. The fact that this derivative shows plasma coagulation ability indicates that the derivative possibly influences directly the general coagulation mechanism, although care should be taken to reach an conclusion due to uncertain factors included in the experimental procedure employed here. A further detailed study will be made in the future.

\section{REFERENCES}

1. Z. A. Rogovin and A. P. Virnik, "Cellulose and Cellulose Derivatives," N. M. Bikales, Ed., Wiley- 
Interscience, New York, N. Y., 1971, Chapter XIX, p 1333.

2. S. Divald and M. M. Joulle, "Medical Chemistry," A. Burger, Ed., 3rd ed, Wiley-Interscience, New York, N. Y., 1970, Chapter 41, p 1092.

3. K. Kamide, K. Okajima, T. Matsui, M. Ohnishi, and H. Kobayashi, Polym. J., 15, 309 (1983).

4. K. Kamide, K. Okajima, T. Matsui, and $\mathrm{H}$. Kobayashi, Polym. J., 16, 259 (1984).

5. D. M. Doddrell and D. T. Pegg, J. Am. Chem. Soc., 102, 6388 (1980).

6. K. Kamide and K. Okajima, Polym. J., 13, 127 (1981).

7. "Blood Coagulation" (Products Guide Book),
International Reagents Corp., 1980, New York, N. Y., pp 11-15, 2-D.

8. R. M. Silverstein, G. C. Bassler, and T. C. Morvill, "Spectrometric Identification of Organic Compounds," 4th ed, Wiley \& Sons Inc., New York, N. Y., 1981.

9. D. Gagunaire, D. Mancier, and M. Vincendon, $J$. Polym. Sci., Polym. Chem. Ed., 18, 13 (1980).

10. K. Kamide, K. Okajima, T. Matsui, and K. Kowsaka, Polym. J., 16, 857 (1984).

11. A. Parfondry and A. S. Perlin, Carbohydr. Res., 59, 39 (1977).

12. K. Kamide, K. Okajima, K. Kowsaka, T. Matsui, S. Nomura, and K. Hikiti, Polym. J., 17, 909 (1985). 